\title{
Status of VICTORIA: NRC Peer Review and Recent Code Applications*
}

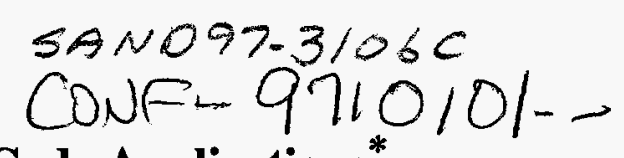

N. E. Bixler

Sandia National Laboratories

Albuquerque, New Mexico 87185-0739

\author{
and J. H. Schaperow \\ Nuclear Regulatory Commission \\ Washington, DC 20555
}

RECEIVED

DEC 221997

OSTI

\begin{abstract}
VICTORIA is a mechanistic computer code designed to analyze fission product behavior within a nuclear reactor coolant system (RCS) during a severe accident. It provides detailed predictions of the release of radioactive and nonradioactive materials from the reactor core and transport and deposition of these materials within the RCS.

A summary of the results and recommendations of an independent peer review of VICTORIA by the U. S. Nuclear Regulatory Commission (NRC) is presented, along with recent applications of the code. The latter include analyses of a temperature-induced steam generator tube rupture sequence and post-test analyses of the Phebus FPT-1 test.

The next planned Phebus test, FPT-4, will focus on fission product releases from a rubble bed, especially those of the less-volatile elements, and on the speciation of the released elements. Pretest analyses using VICTORIA to estimate the magnitude and timing of releases are presented. The predicted release of uranium is a matter of particular importance because of concern about filter plugging during the test.
\end{abstract}

\subsection{Introduction}

Release of radionuclides into the atmosphere is the main concern in the event of a nuclear reactor accident. The consequences of a severe accident depend on the quantity, characteristics, and timing of the releases of radionuclides from the reactor coolant system (RCS) into the containment, and finally into the atmosphere. In a by-pass accident, releases by-pass the containment and go directly from the RCS into an auxiliary building or into the atmosphere. As a result, accurate determination of the quantity of fission products that are retained in the primary and secondary circuits and containment is paramount to the assessment of risk.

The physical processes that influence the quantity and timing of a release are complex. In order to predict the outcome of a nuclear accident, it is necessary to accurately model as many of the relevant physical processes as possible. VICTORIA [1] is a mechanistic computer code designed to model such processes so that the magnitude, speciation, physical properties, and timing of fission product releases can be predicted.

*This work was supported by the U.S. Nuclear Regulatory Commission and was performed at Sandia National Laboratories, which is a multiprogram laboratory operated by Sandia Corporation, a Lockheed Martin Company, for the U. S. Department of Energy under Contract DE-AC04-94AL85000. 


\section{DISCLAMIER}

Portions of this docroment mosy be illegible in elecronic iroge products. Images are produced from the best available original doecoment 
VICTORIA does not predict thermal hydraulics, but requires such information as input. The heart of the code is in its mechanistic treatment of fission product release from fuel, chemistry, aerosol physics, transport, and decay heating. The coupled treatment of these phenomena make VICTORIA unique in its predictive capabilities.

The U.S. Nuclear Regulatory Commission (NRC) recently conducted a peer review to assess the code and documentation against a set of design objectives and targeted applications, and to make recommendations on how the code could be improved [2]. While the results of the review (completed in April 1997) confirm the overall adequacy of the VICTORIA code, the review committee made a number of recommendations for model improvements. These were ranked as findings and concerns. A plan for addressing these recommendations is discussed in Section 2 . Some of these modifications have already been implemented.

The version of VICTORIA that was reviewed (version 1.0) is very similar to the current release (VICTORIA 92-01) but contains a few minor corrections and extensions. Versions used in this work are VICTORIA 1.1 and 1.2. The significant difference between versions 1.0 and 1.1 is that the latter was modified to optionally treat multiple condensed phases. In addition, VICTORIA 1.2 uses Blackburn's thermochemical model to represent oxidation and volatilization processes of the uranium fuel matrix.

Three applications of VICTORIA are discussed in Section 3. These are analyses of an induced steam generator tube rupture (ISGTR) sequence, the Phebus FPT-1 test, and the Phebus FPT-4 test, respectively. The FPT-1 test was conducted in Cadarache, France, in June 1996 and is a midscale, in-pile, integral test. The FPT-4 test will be conducted in 1998 and will use a preformed rubble bed rather than fuel rods. Both tests use spent fuel from the Belgian BR-3 reactor. Section 4 provides a summary of the current status of VICTORIA development and recent applications of the code.

\subsection{Peer Review Recommendations and Planned Response}

The process followed by the peer review committee (PRC) was very similar to that of previous independent peer reviews of NRC codes. The starting point was a set of targeted applications and design objectives that was provided by the NRC with input from the code developers. The targeted applications included (1) experimental simulation, (2) benchmarking of the MELCOR systems-level code, and (3) analysis of full-scale plant sequences. The first of these is necessary to validate and assess the models that make up the VICTORIA code. The third targeted application is necessary to achieve the second. Together they define the ultimate purpose of the code, namely, to be able to evaluate accident sequences and to apply lessons learned to other tools that are used for accident analysis and evaluation. The design objectives are very similar to ones used in previous peer reviews for the NRC.

The review was conducted in four steps: (1) a bottom-up review of the detailed models that comprise the VICTORIA code; (2) an evaluation of VICTORIA by running a series of calculations on a simple test problem; (3) a top-down review of the performance of the code on full-scale plant analyses performed by the developers; and (4) a review of the code manual and other code documentation. The results of each of these steps are described in the PRC report [2] and are ranked as findings, high-priority concerns, mediumpriority concerns, and lower-priority concerns. Tables 1 through 4 list these findings and concerns and indicate when the item will be addressed by the code developers. All of the items in Tables 1 and 2, the findings and high-priority concerns, will be addressed prior to the release of the next code version, which 
will be named VICTORIA 2.0. Some of the medium- and lower-priority concerns may also be addressed if time permits, as indicated in Tables 3 and 4.

\subsection{Findings}

The first three findings involve removing outdated and unused options from the code. The first recommendation in the findings is to remove the optional, highly mechanistic, fission product release models [3] because the mechanisms treated by these models are poorly understood. Furthermore, these models have not been used by any of the VICTORIA users. The second recommendation is to remove the option to model the chemistry of fission products in fuel grains. While there seems to be some controversy among the experts on whether chemical interactions between fission products and the $\mathrm{UO}_{2}$ grain lattice are physical, the PRC is convinced that they are not. The code developers had previously abandoned the ingrain chemistry model on pragmatic grounds; validation studies against data from the Oak Ridge National Laboratory horizontal induction (HI) and vertical induction (VI) and the Sandia National Laboratories source term (ST) fission product release tests showed that the option to model fission product chemistry in the fuel pores, but not in the fuel grains, provides better agreement with the data [4]. The third recommendation is to remove an outdated option that allows the user to directly input mass and momentum boundary layer thicknesses. The existing option that is favored is to use standard correlations to determine the thicknesses of these layers.

Table 1. Findings

\begin{tabular}{|c|l|l|}
\hline Finding No. & \multicolumn{1}{|c|}{ Description } & \multicolumn{1}{|c|}{ Status } \\
\hline \hline 1 & Remove optional fission-product release models & Done \\
\hline 2 & Remove option to model chemistry in fuel grains & Done \\
\hline 3 & $\begin{array}{l}\text { Remove option to directly specify mass and momentum } \\
\text { boundary layer thicknesses }\end{array}$ & Done \\
\hline 4 & Make resuspension model optional & Done \\
\hline 5 & $\begin{array}{l}\text { Add warnings on time step and thermal-hydraulic input } \\
\text { errors }\end{array}$ & In VICTORIA 2.0 \\
\hline 6 & Rewrite user's manual & In VICTORIA 2.0 \\
\hline
\end{tabular}

The fourth finding involves making the aerosol resuspension model optional. This recommendation was made because in nearly all cases the aerosols that deposit are mixtures of liquid and solid phases; on the other hand, resuspension models are based on data for dry-dust aerosols [5]. The PRC also recommended that warnings be issued if the user specifies a time step that exceeds the Courant limit and when thermal-hydraulic inputs are not self-consistent. Finally, the PRC recommended that a new code manual be written to correspond to version 2.0 , which will have a number of revisions since the previous version, VICTORIA 92-01. These last two modifications will be completed before VICTORIA 2.0 is released in mid-1998. 


\subsection{High-Priority Concerns}

The PRC believes that three separate condensed phases will form rather than a single one, as modeled in previous versions of the code. More specifically, their recommendation is to model an oxidic phase, a metallic phase, and a third phase containing only cesium iodide. This recommendation has been implemented [6] and is demonstrated in the applications discussed later. They also recommend adding a model for fission product solubility in the fuel. Their second high-priority recommendation is that the sensitivity of results to "chemistry film" thickness be investigated and if the sensitivity is found to be unacceptable, that the numerical treatment be modified to eliminate these films. The "chemistry films" are currently used as a numerical device to allow chemical equilibrium to be calculated for fixed mass and fixed volume systems. The model for treating fission product solubilities in fuel has not been implemented and the effect of "chemistry films" has not been investigated, but these items will be completed before VICTORIA 2.0 is released.

Table 2. High-Priority Concerns

\begin{tabular}{|c|l|l|}
\hline Concern No. & \multicolumn{1}{|c|}{ Description } & \multicolumn{1}{|c|}{ Status } \\
\hline \hline $1 \mathrm{a}$ & Treat multiple condensed phases & Done \\
\hline $1 \mathrm{~b}$ & Treat solubility of fission products in fuel & In VICTORIA 2.0 \\
\hline 2 & Investigate and, if necessary, remove "chemistry films" & In VICTORIA 2.0 \\
\hline
\end{tabular}

\subsection{Medium-Priority Concerns}

Four medium-priority concerns were listed by the PRC. These items are expected to have a lesser impact on VICTORIA predictions than the findings and high-priority concerns. The first of the recommendations from the medium-priority concerns is to make a number of modifications to the thermochemical database. The second is to revise the treatment of uranium thermochemistry; the PRC preference is to implement Blackburn's method [7]. This has already been done for hyperstoichiometric fuel $\left(\mathrm{UO}_{2+\mathrm{x}}, \mathrm{x}>0\right)$ because of concern about potential uranium volatilization in the Phebus FPT-4 test. At this point, it is not certain whether this model will be extended to treat hypostoichiometric fuel $(x<0)$ prior to the release of VICTORIA 2.0. The third medium-priority concern is in connection with boron carbide control blades and rods. Currently, the thermochemical database does not contain carbon and so cannot treat formation of carbonates of the fission products. The PRC recommended that the importance of carbon chemistry be investigated and, if necessary, that carbon species be added to the database before analyzing sequences in which boron carbide is present. The fourth medium-priority concern is connected with fission product release from fuel. The PRC recommended that appropriate values for grain diffusivities, interconnected porosities, and fuel permeabilities be investigated for a range of fuel burnups and levels of excess oxygen. They also recommend validating the pressure dependence of the VICTORIA release model. Responses to all of the medium-priority concerns, with the exception of revision of the fuel thermochemistry, are planned as future activities, i.e., following the release of VICTORIA 2.0. 
Table 3. Medium-Priority Concerns

\begin{tabular}{|c|l|l|}
\hline Concern No. & \multicolumn{1}{|c|}{ Description } & \multicolumn{1}{c|}{ Status } \\
\hline \hline 1 & Modify Gibbs free-energy data & Future \\
\hline 2 & Revise treatment of fuel thermochemistry & Done for $\mathrm{x}>0$ \\
\hline 3 & Investigate and, if necessary, add carbon species & Future \\
\hline $4 \mathrm{a}$ & $\begin{array}{l}\text { Additional investigation of values affecting fission product } \\
\text { release from fuel }\end{array}$ & Future \\
\hline $4 \mathrm{~b}$ & Validate pressure dependence of release model & Future \\
\hline
\end{tabular}

\subsection{Lower-Priority Concerns}

The PRC identified five lower-priority concerns and made the following recommendations. The first of these is to add uranic acid to the database. This may be done prior to release of VICTORIA 2.0 because it should take a relatively short time to implement. The second item is to add a diffusion-based cladding oxidation model as an option to the current Urbanic and Heidrick model [8]. This new model would be along the lines of a recent modification to SCDAP/RELAP5 (SR5) [9]. The third recommendation is to investigate and, if necessary, correct for the fact that thermal-hydraulic codes may not model changes in gas velocities caused by release of fission products from the core. The fourth recommendation is to update uranium oxidation and volatilization models based on Blackburn's model. Again, this has already been done for $x>0$. The final recommendation is to allow more user control over the fraction of decay heat that is deposited in fission product films and adjoining structures. All but the first and fourth of these items will be addressed after the release of VICTORIA 2.0.

Table 4. Lower-Priority Concerns in Independent Peer Review Report

\begin{tabular}{|c|l|l|}
\hline Concern No. & \multicolumn{1}{|c|}{ Description } & \multicolumn{1}{c|}{ Status } \\
\hline \hline 1 & Add uranic acid to database & In VICTORIA 2.0? \\
\hline 2 & $\begin{array}{l}\text { Add diffusion-based model for cladding oxidation and } \\
\text { hydriding }\end{array}$ & Future \\
\hline 3 & Investigate and, if necessary, correct gas velocity data & Future \\
\hline 4 & Update fuel oxidation and volatilization models & Done for $\mathrm{x}>0$ \\
\hline 5 & Make decay-heating model more flexible & Future \\
\hline
\end{tabular}




\subsection{Recent Applications of VICTORIA}

\subsection{ISGTR Sequence in Surry Reactor Plant}

SCDAP/RELAP5 [9] analyses were performed to evaluate the potential for an ISGTR during the early stages of a station blackout sequence [10]. Reference 9 documents 7 cases. Case 6 was chosen as the basis for this work. The specific characteristics of Case 6 are as follows: (1) the secondary side of loop C (the one with the pressurizer, hereafter denoted the faulted loop) depressurizes early in the sequence due to a stuck-open atmospheric dump valve (ADV) and (2) the primary remains at full system pressure even after the surge line and hot leg nozzle are predicted to fail by creep rupture. Table 5 shows the timing of major events, as predicted by SR5. Originally, the calculation was terminated at the point of pressurizer surge line failure; however, the actual thermal-hydraulic calculation used as the basis for this study was extended until reactor vessel lower head failure. VICTORIA 1.1 was used to analyze the release of fission products from the core and their transport through the primary circuit, secondary circuit, and out through the stuck-open ADV [11]. The objective of this calculation was to assess offsite releases for a regulatory initiative on steam generator tube integrity.

Table 5. Sequence of Events in ISGTR Sequence

\begin{tabular}{|l|r|}
\hline \multicolumn{1}{|c|}{ Event } & Time (s) \\
\hline \hline Station blackout initiates sequence & 0 \\
\hline ADV sticks open on loop C & 20 \\
\hline Onset of PORV cycling & 1,960 \\
\hline Hot leg natural circulation of steam begins & 9,090 \\
\hline Fuel rod oxidation begins & 11,620 \\
\hline Surge line fails by creep rupture, but failure is ignored & 13,730 \\
\hline Faulted loop (C) SG tube fails by creep rupture & 14,960 \\
\hline Faulted loop hot leg nozzle melts, end of VICTORIA calculation & 33,750 \\
\hline
\end{tabular}

Figure 1 shows a schematic representation of the VICTORIA nodalization of the Surry reactor vessel and primary circuits. A total of 48 nodes are used to represent the domain. The unfaulted loops, A and B, are represented as a single loop since the thermal-hydraulic behavior in the two loops is almost identical. The faulted loop, $\mathrm{C}$, which is the one with the pressurizer, is represented individually. 


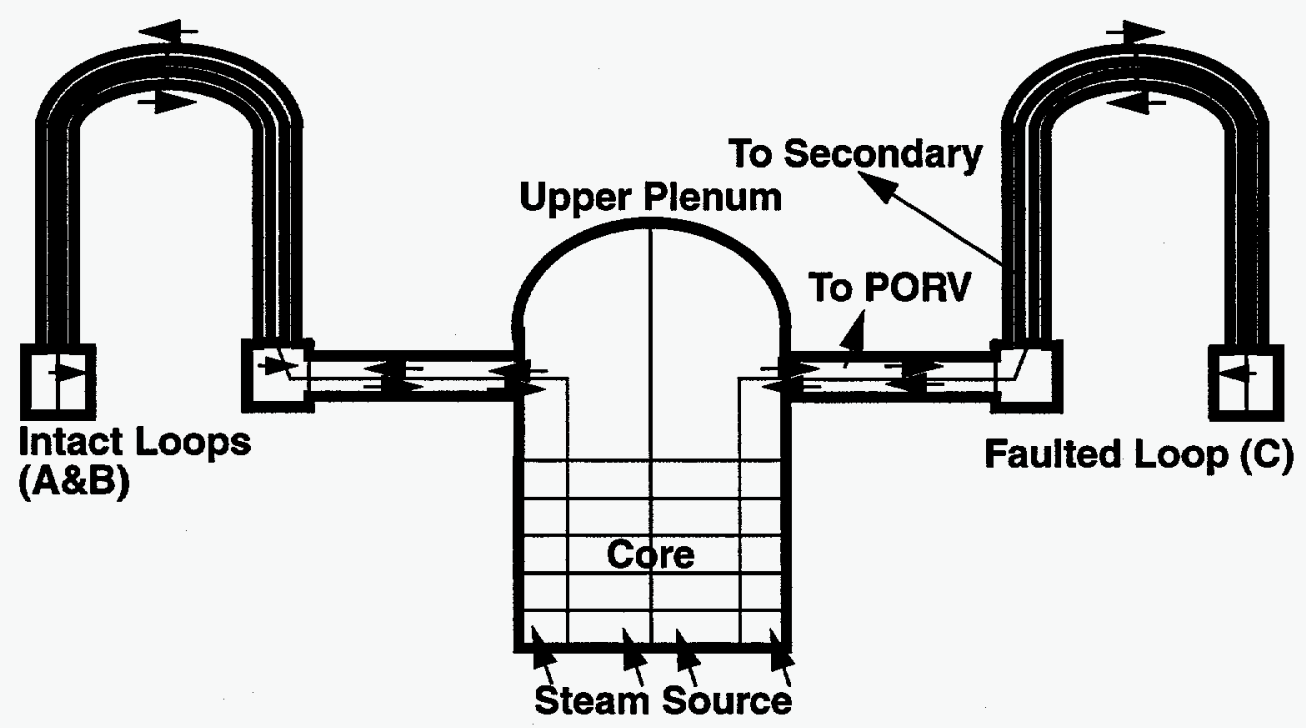

Figure 1. Schematic of the VICTORIA representation of the Surry reactor vessel and primary circuits.

During this sequence, periodic accumulator injection maintains a water level that fluctuates between the bottom of the core and about $40 \%$ of the height of the core. This water vaporizes, providing the source of steam to the core and primary circuits. Steam losses occur through the pressurizer and out through the pressure-operated relief valve (PORV) or through the broken steam generator tube, as indicated in Figure 1. The losses through the PORV and broken steam generator tube are distinct in time. Early losses occur through the PORV, which cycles until the steam generator tube rupture occurs. After that time, the system begins to depressurize and PORV cycling ceases.

Figure 2 shows the VICTORIA nodalization of the faulted secondary circuit. Four nodes represent this region: one for the steam separators, one for the steam dryers, and two for the long steam line. Coolant exiting from the primary flows into node 1 ; coolant exits from node 4 through the stuck-open ADV and into the environment.

Figure 3 shows the VICTORIA-predicted fission product release histories. Also shown in this figure is the peak core temperature history. Sudden reductions in the core temperature correspond to accumulator injections. By the end of the transient, peak core temperatures exceed $2700 \mathrm{~K}$ while the bottom $40 \%$ of the core is sufficiently cooled that little fission product release occurs from this region. 


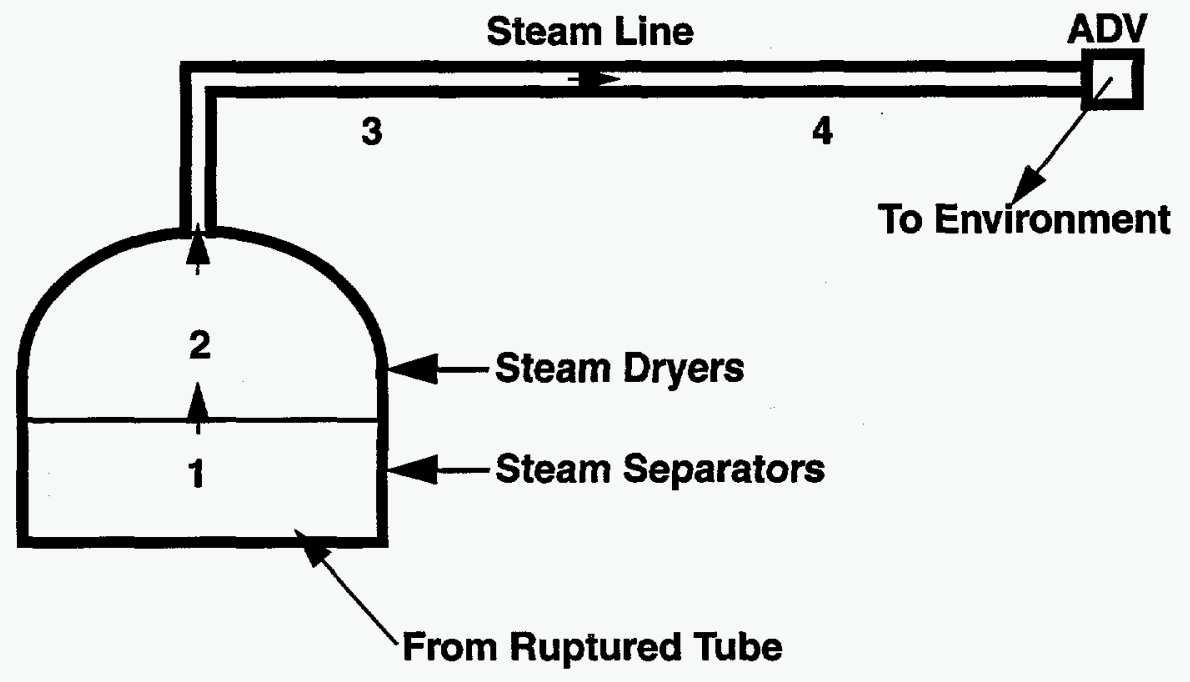

Figure 2. Schematic of the VICTORIA representation of the Surry faulted secondary circuit.

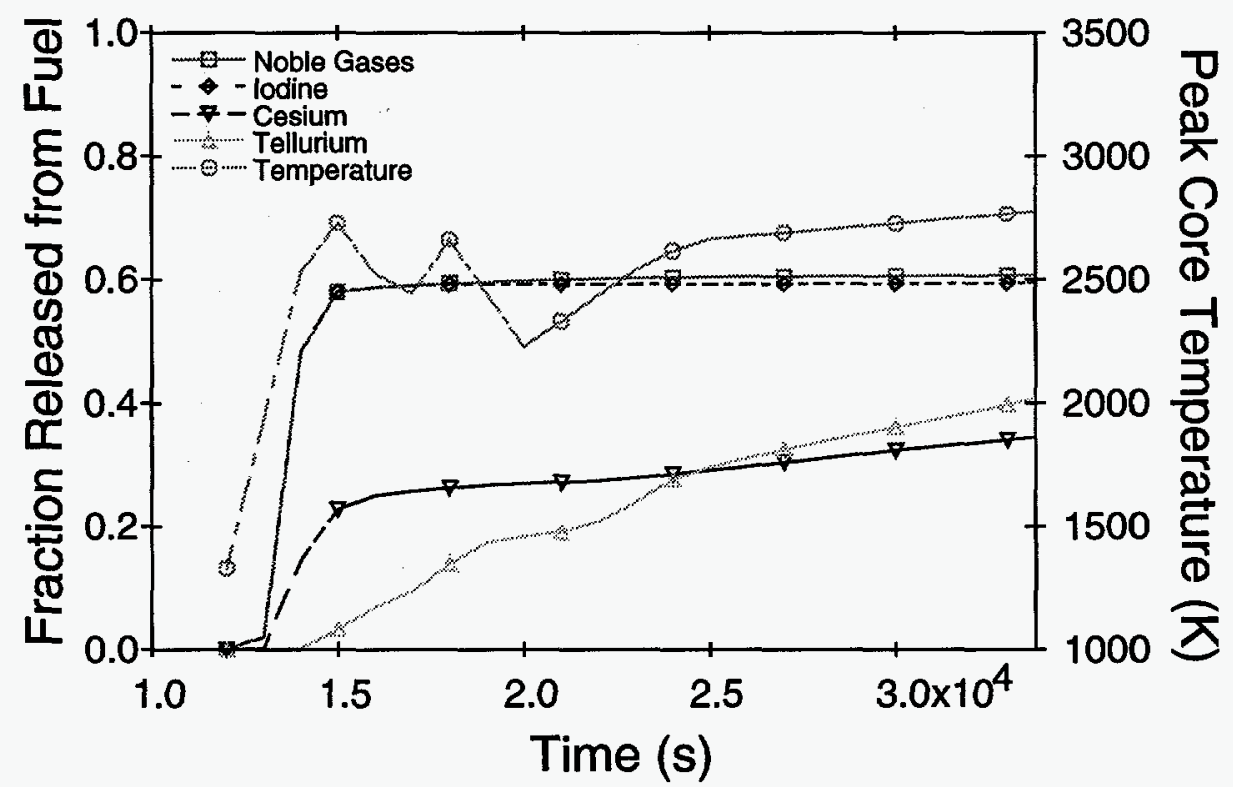

Figure 3. VICTORIA-predicted peak core temperature and fission product release histories from fuel for ISGTR sequence.

Fractional releases of the noble gases and iodine occur very early and ultimately reach $60 \%$. Releases of these elements from the upper $60 \%$ of the core are nearly complete; releases from the bottom $40 \%$ of the core are minimal because of the lower temperatures there. Cesium and tellurium releases are 
more protracted than those for the noble gases and iodine. Final release fractions for these elements are about $35 \%$ and $40 \%$, respectively.

VICTORIA-predicted releases to the environment are shown in Figure 4. The noble gas releases to the environment are predicted to be only about $12 \%$; the balance of the noble gases that are released from the core are predicted to exit the RCS through the PORV. Iodine release to the environment is predicted to be much higher, about $30 \%$. This is because much of the iodine, in the form of cesium iodide, condenses onto the relatively cold structural surfaces. Later, as these surfaces heat up, the iodine revaporizes. Thus, even though noble gas and iodine fractional release histories from core are nearly identical, more iodine is released to the environment because it is retained within the RCS until after PORV cycling ceases. Cesium and tellurium are retained to a greater extent in the RCS than is iodine; their release fractions are predicted to be only about $8 \%$ and $12 \%$, respectively. Other less volatile fission products are predicted to be released at even smaller fractions. Fission product release to the environment occurs over a 4- to 5-h interval.

Little retention of the volatile elements--iodine, cesium, and tellurium--is predicted to occur in the faulted secondary circuit. This is because temperatures throughout the secondary circuit exceed $1250 \mathrm{~K}$ by the end of the transient; at these temperatures, the more volatile species, such as cesium iodide, remain in the vapor phase and so cannot deposit. Primary circuit temperatures are even higher by the end of the transient, e.g., the hot leg nozzle on the faulted loop is predicted to exceed its melting point, which is more than $1700 \mathrm{~K}$.

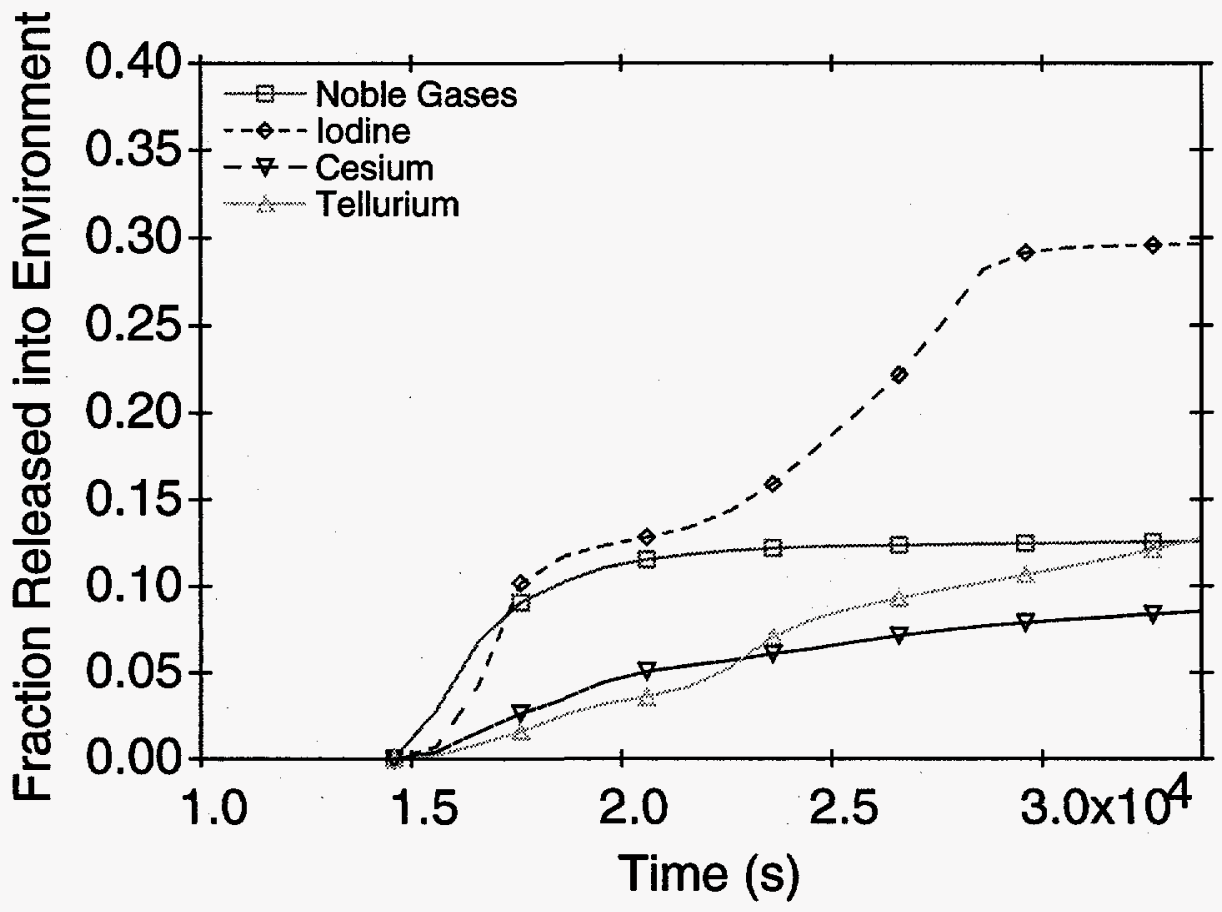

Figure 4. VICTORIA-predicted fission product releases to the environment for ISGTR sequence. 


\subsection{Phebus FPT-1 Test}

Phebus is an experimental reactor located in Cadarache, France. A series of six tests, the FP series, is scheduled to be conducted there. The first test, FPT-0, was run in December 1993. The second test, FPT-1, was run in July 1996. The primary difference between FPT-0 and FPT-1 is that FPT-0 was a shakedown test using trace irradiated fuel while FPT-1 used spent fuel from the BR-3 reactor in Belgium.

The Phebus FP tests are integral in nature, i.e., they attempt to represent all of the processes that would take place during a severe nuclear accident. A schematic of the Phebus FP apparatus is shown in Figure 5. It consists of an in-pile fuel bundle containing 20 fuel rods and 1 control rod, all $1 \mathrm{~m}$ long, an upper plenum, a steam-generator tube, a containment vessel, and interconnecting pipework.

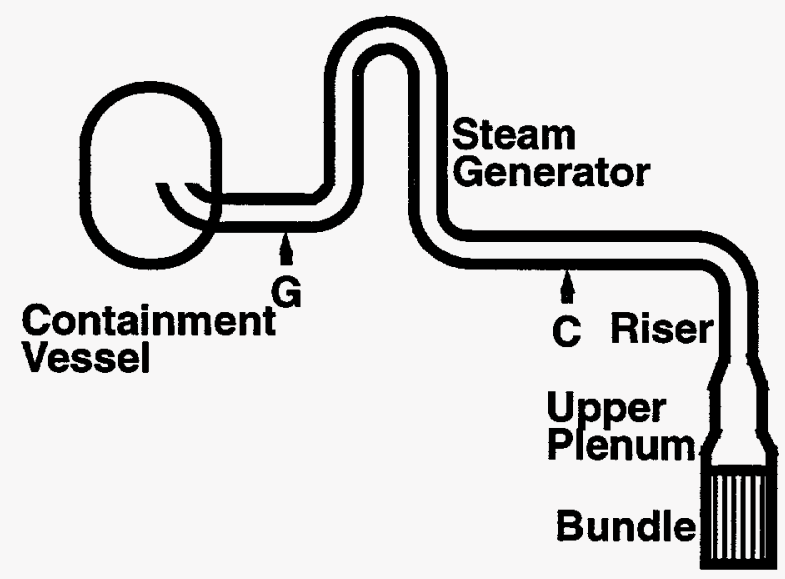

Figure 5. Schematic of the Phebus FPT-1 test configuration.

While the FPT-1 test was run about a year ago, data are just becoming available for fission product releases and deposition in the circuit. To the extent that data are available, they are compared with predictions. The primary purpose for the analyses presented here is to validate the VICTORIA code. Further comparisons will be made as more data become available.

VICTORIA [1] analyses of the Phebus FPT-1 test were performed for two regions [12]: (1) the fuel bundle, represented by ten nodes in two rings, and (2) the upper plenum and circuit leading to containment, represented by fourteen nodes in one ring. Figures 6 and 7 show the VICTORIA representations used for the FPT-1 fuel bundle and primary circuit, respectively. The reasons for subdividing the domain were as follows: (1) to reduce the CPU time required for the individual calculations; (2) to allow sensitivity studies to be conducted separately on the two subdomains; and (3) to allow different radial nodalizations for the two subdomains, i.e., two radial rings in the fuel bundle and one radial ring in the circuit.

Two options were employed to facilitate the analyses of FPT-1. The first of these was the boundary coupling option [13], which was used to couple the two-ring representation of the fuel bundle with the onering representation of the circuit. With this option, the mass flow rates of vapors and aerosols leaving the top of the fuel bundle were written as a data file; these values were then read, summed over the two rings, and used as vapor and aerosol sources in the first node of the single ring in the circuit analysis. 


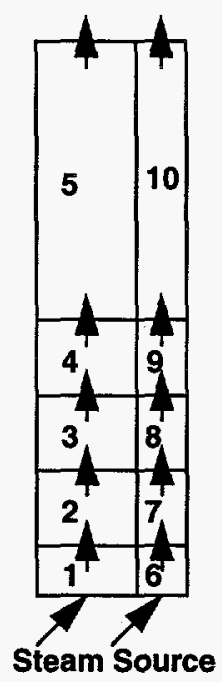

Figure 6. Schematic of the VICTORIA representation of the Phebus FPT-1 fuel bundle.

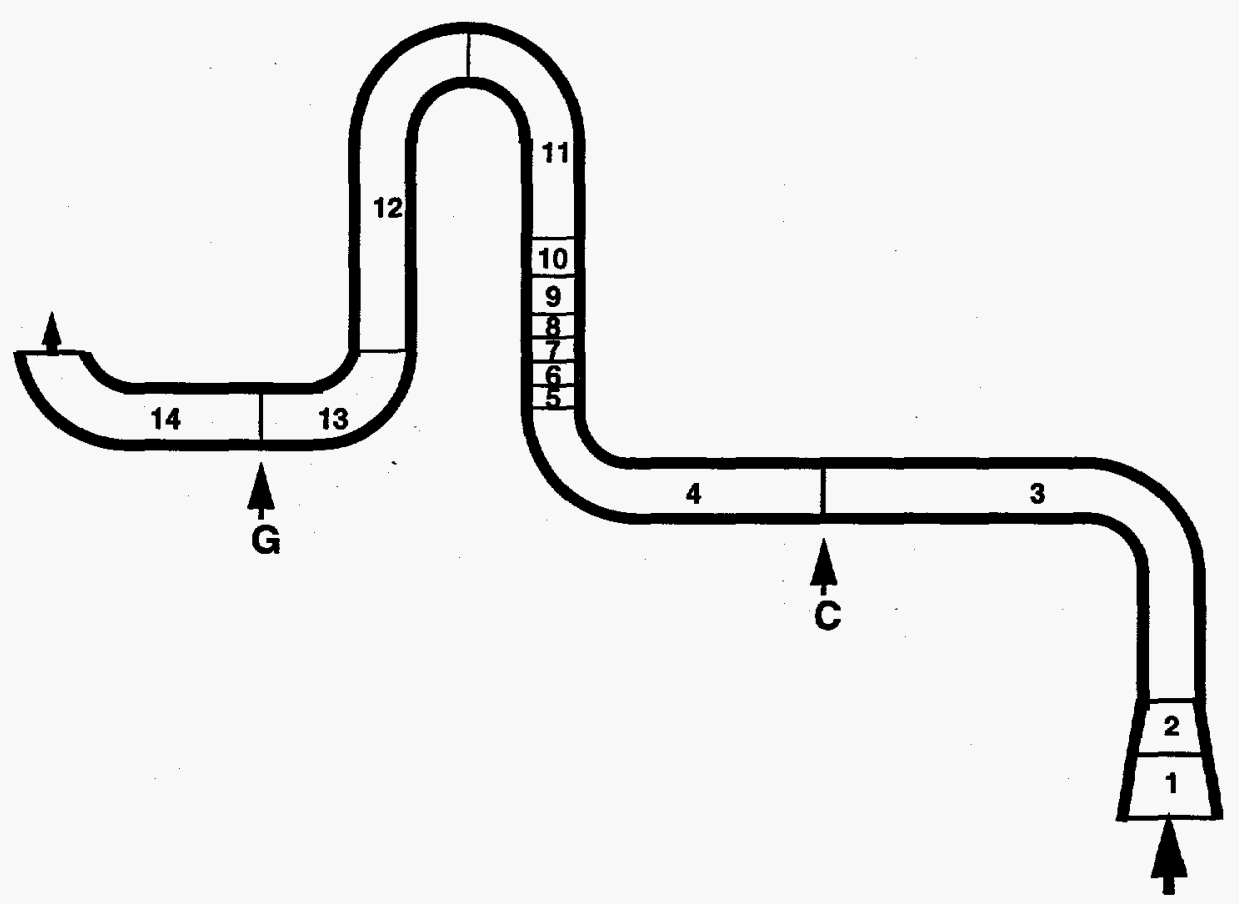

Figure 7. Schematic of the VICTORIA representation of the Phebus FPT-1 primary circuit. 
In the second option, velocities for each node in the circuit were automatically calculated based on the mass source rates. Velocities in each node were calculated so that the flow of vapors out of each cell equaled the flow of vapors into it, i.e., there was no accumulation or depletion of vapor within a cell. The combination of these two techniques allows the analyst to perform the circuit calculation without any input of transient source or flow rate data.

Figure 8 compares release predictions using models for a single condensed phase and for three condensed phases with preliminary experimental data. No data are currently available for the noble gases, antimony, or strontium. For most of the fission products, the agreement between predictions and data is remarkable, regardless of the number of condensed phases modeled. Minor improvements in agreement with most of the data can be observed for the three condensed-phase treatment.

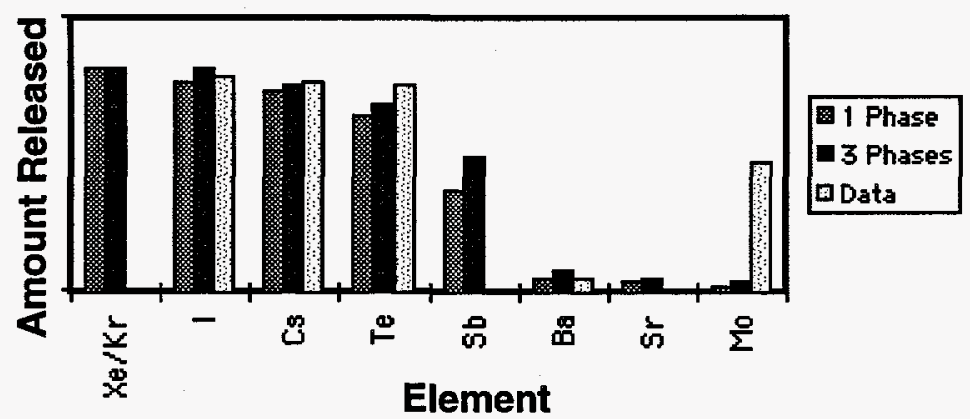

Figure 8. Comparisons of VICTORIA-predicted fission product release predictions using models for one- and three-condensed phases with preliminary experimental data.

A notable exception to this agreement is for molybdenum. While agreement for the three condensedphase model is slightly better, releases are underpredicted by more than an order of magnitude for both cases. The reason for this discrepancy is not known at present, but bears further investigation. The most likely possibilities are that the preliminary data for molybdenum release are too high, thermochemical data for one or more molybdenum species are not well quantified, or a volatile molybdenum species is not included in the current VICTORIA thermochemical database. A weakness in the first of these possibilities is that similar molybdenum releases have been reported for the VERCORS test series [14].

Figures 9 and 10 show the effect of the number of condensed phases modeled on the predicted deposition pattern of iodine in the hot leg of the steam generator tube. Values are expressed as fractions of the initial core inventory. 


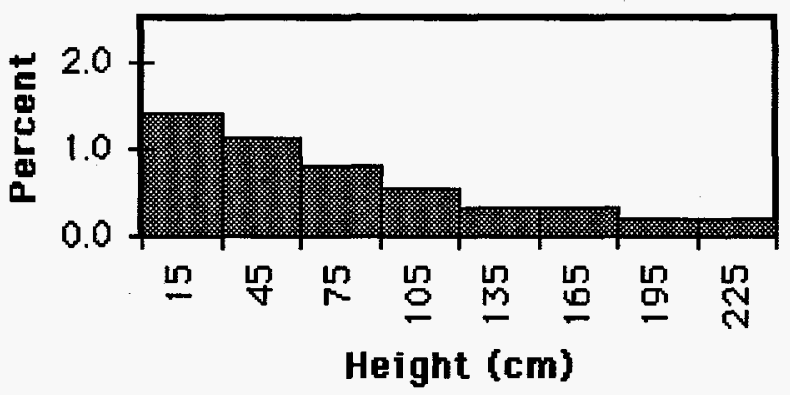

Figure 9. VICTORIA-predicted iodine deposition pattern in the steam generator tube hot leg for the one condensed-phase model.

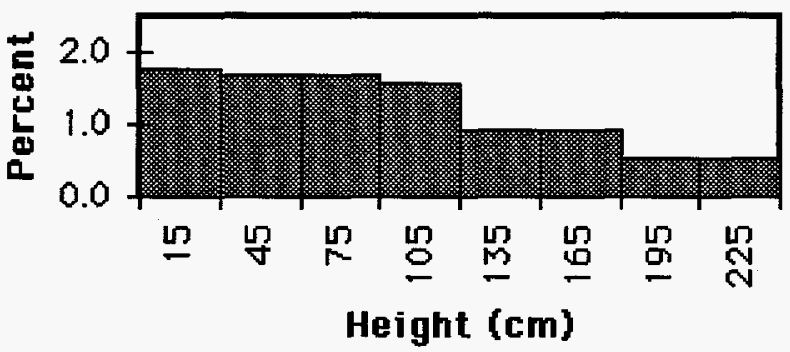

Figure 10. VICTORIA-predicted iodine deposition pattern in the steam generator tube hot leg for the three condensed-phase model.

While the deposition profiles are not dramatically different for the two cases shown in Figures 9 and 10, there are some important distinctions. Using the one condensed-phase model, iodine, which is primarily present as cesium iodide, begins to condense upstream of the steam generator tube. At the inlet to the tube, most of the cesium iodide is in the condensed phase, i.e., is an aerosol. The dominant mechanism for deposition of iodine in the steam generator tube is aerosol deposition by thermophoresis. In the prediction using the three condensed-phase model, iodine is again chiefly in the form of cesium iodide. However, most of the cesium iodide enters the steam generator tube as a vapor. This difference is because cesium iodide is treated as a pure phase in the three-phase model. Since cesium iodide enters the steam generator tube as a vapor, the dominant deposition mechanism is condensation onto the tube surface. The profile is flatter at the inlet of the steam generator in this case than for a single condensed phase because of the difference in deposition mechanisms. Predicted releases into containment are shown in Figure 11 using the three condensed-phase option. Values are in arbitrary units. 


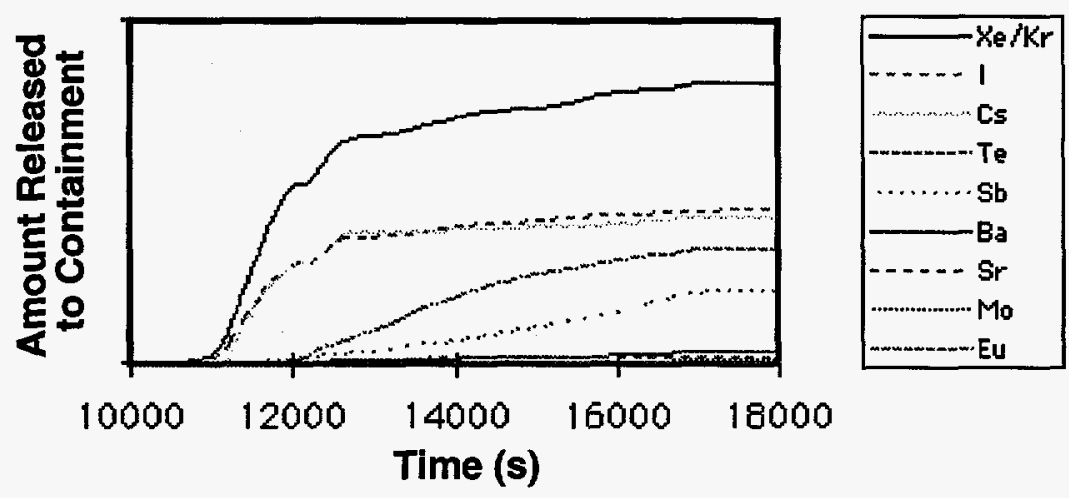

Figure 11. VICTORIA-predicted integral releases into containment for three condensed-phase model.

While deposition patterns and mechanisms are somewhat different for the two models, overall retention in the circuit is very similar. Predicted releases into containment for the single condensed-phase option are nearly the same as those shown in Figure 11 for most of the fission product elements. The largest difference is for iodine; about $30 \%$ more of the iodine inventory is predicted to be retained in the circuit using the single-phase option than using the three-phase option. When experimental data become available, they should be useful for determining which option better predicts overall deposition patterns in the FPT-1 circuit.

\subsection{Phebus FPT-4 Test}

Figure 12 shows a schematic of the Phebus FPT-4 test apparatus in the currently proposed, simplified configuration. The FPT-4 test is significantly different from the other tests in the Phebus FP series because it uses a preformed rubble bed rather than a bundle of fuel rods. Its purpose is primarily quantifying fission product release from a rubble bed rather than fission product behavior in the circuit, as in the other Phebus FP tests.

The rubble bed is to be composed of $80 \%$ fuel and $20 \%$ zirconia by mass. Because of safety considerations, the bottom third of the rubble bed is to be formed with depleted uranium; the top two-thirds is to be formed from three-cycle spent fuel from the Belgian BR-3 reactor. A bank of filters, illustrated in Figure 12, is intended to capture fission products upstream of the $90^{\circ}$ bend located at the top of the riser. These filters effectively isolate most of the test circuit.

DEBRIS was used to provide the thermal-hydraulic data for VICTORIA [15]. (DEBRIS is a code developed at Sandia National Laboratories for the U.S. NRC to predict thermal-hydraulic behavior, including fuel melting and relocation, in a debris bed.) This calculation was done using the very fine nodalization shown in Figure 13. Overlaid on the DEBRIS nodalization is the coarser VICTORIA nodalization, shown by the thicker lines, which contains 16 nodes, 4 radial by 4 axial. The VICTORIA nodalization does not include the unenriched fuel region because temperatures reach only slightly more than $1000 \mathrm{~K}$ in this region, which is too low for fission product behavior or uranium volatilization to be important. Uranium volatilization is a primary concern for the FPT-4 test because of the potential for 
clogging the filters in the filter bank. The current plan is to use 4 or 5 filters, each of which will be active over a portion of the transient.

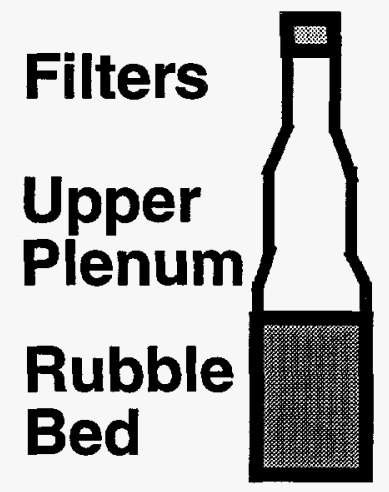

Figure 12. Schematic of the Phebus FPT-4 test configuration.

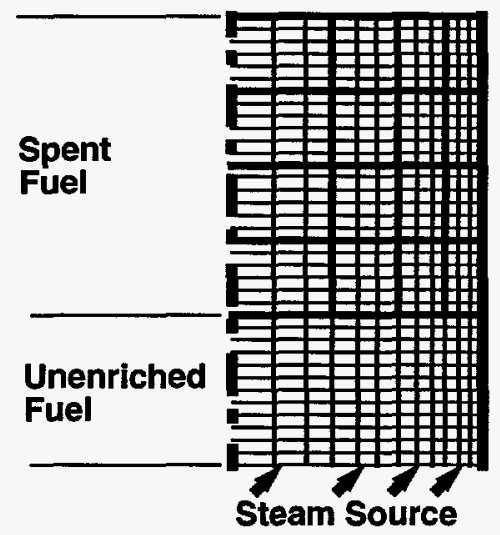

Figure 13. Schematic of the DEBRIS and VICTORIA representations of the Phebus FPT-4 test configuration.

A snapshot of the final debris bed configuration, as predicted by the DEBRIS code, is shown in Figure 14. The key features of the end state are a molten pool that penetrates down to about $15 \mathrm{~cm}$ above the depleted uranium zone, a large void region just above the molten pool, and a 2-cm-thick permeable crust above the void zone. DEBRIS predicts that the crust will survive the test, but this prediction is rather uncertain. If the crust collapses during the test, then a dense crust will form over the top of the molten pool. This would modify the thermal-hydraulic predictions and as a result the release predictions discussed below. 


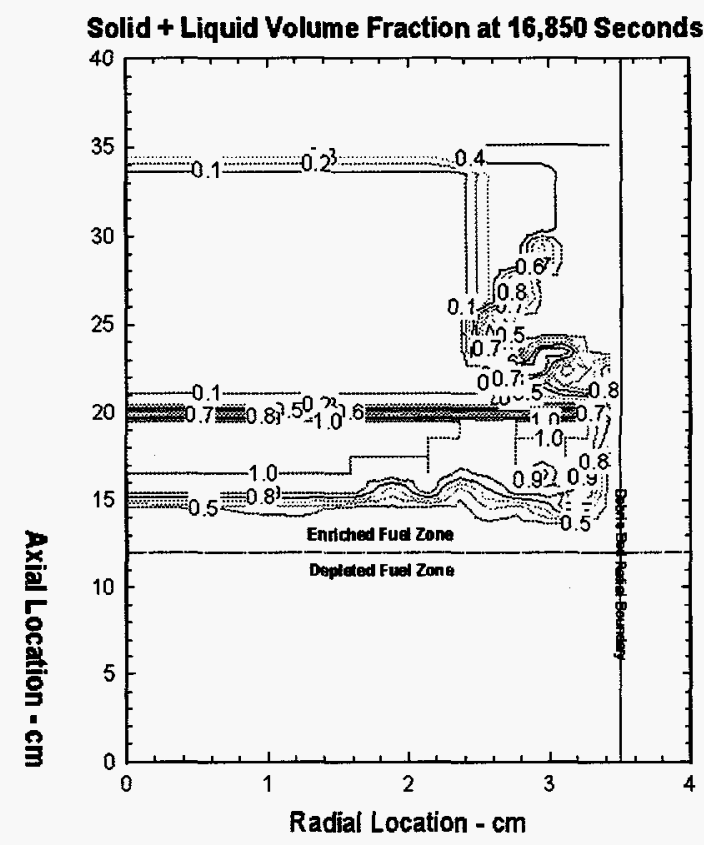

Figure 14. DEBRIS-predicted solid plus liquid volume fractions.

Figure 15 shows temperature and fission product release histories for the FPT-4 test. The temperature corresponds to the top centerline position of the debris bed. This represents the peak temperature in the debris bed through the plateau at $2700 \mathrm{~K}$; after this time, the peak temperature is in the molten pool, which gradually moves downward to its final position, as shown in Figure 14. The small bump in the temperature history near the end of the transient shown in Figure 15 corresponds to a larger thermal ramp in the interior of the debris bed, where temperatures peak at over $3000 \mathrm{~K}$.

Fission product fractional releases are shown in Figure 15 for barium, molybdenum, strontium, and ruthenium. Significant releases of these elements begin during the ramp leading to the $2700 \mathrm{~K}$ plateau shown in the figure and accelerate during the final ramp leading to melting. Significant release fractions of the less volatile fission products are predicted: about $60 \%$ for barium and about $30 \%$ for molybdenum and strontium. Release of ruthenium is predicted to be less than $1 \%$. It is possible that the FPT-4 test will continue to $18,000 \mathrm{~s}$ if filter clogging is not a problem. If this is the case, releases will be even higher than those shown in Figure 15.

The VICTORIA-predicted integral uranium mass release history is shown in Figure 16. Up to the endpoint of this calculation at $16,800 \mathrm{~s}$, about $115 \mathrm{~g}$ of uranium release are predicted. This corresponds to loss of about $130 \mathrm{~g}$ of $\mathrm{UO}_{2}$. If the test is continued longer, uranium releases can be extrapolated since the release rate is nearly constant during the final plateau. 


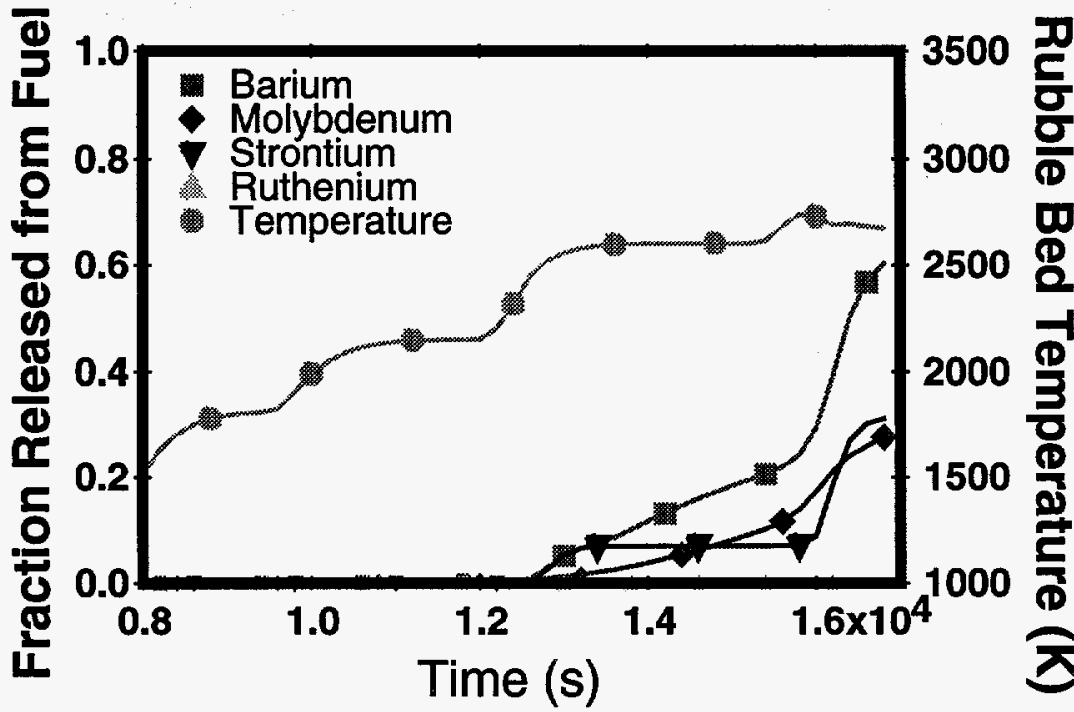

Figure 15. VICTORIA-predicted temperature and integral, fractional, fission-product release histories for Phebus FPT-4. Temperature is at the top centerline of the debris bed.

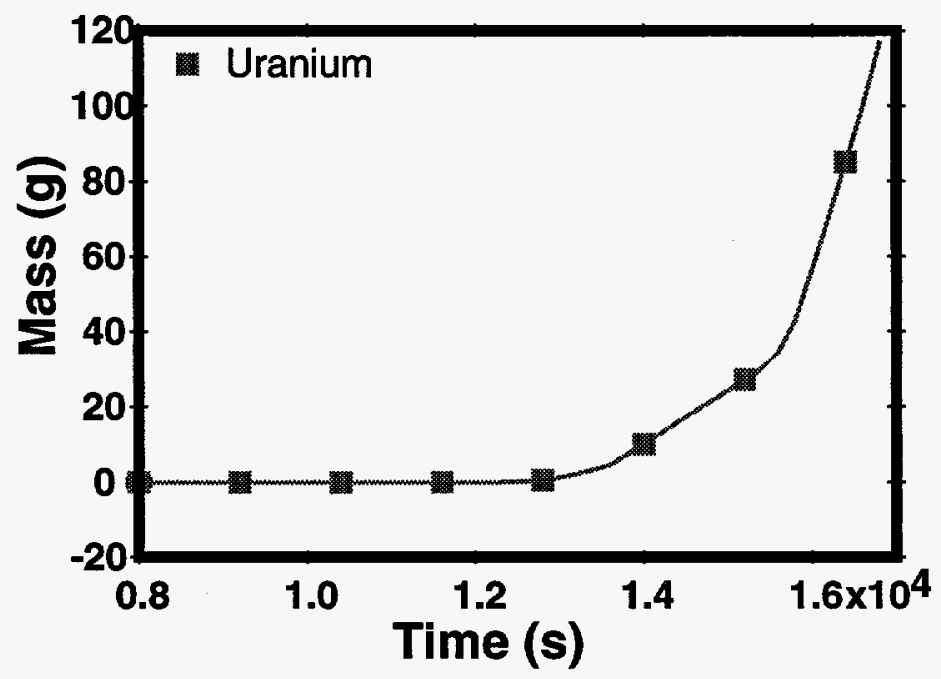

Figure 16. VICTORIA-predicted integral, uranium, mass release histories for Phebus FPT-4.

The predictions shown here are significant for the Phebus program in several ways. First of all, the release predictions indicate that FPT-4 should be a very useful test because releases of the less volatile, refractory elements are predicted to be much greater than for the other Phebus FP tests. The large predicted releases for FPT-4 are due to the high temperatures and to the direct contact between fuel particles and steam. Uranium release predictions are especially significant for the Phebus project because of concern about plugging the filters. The current work indicates that less than $150 \mathrm{~g}$ of $\mathrm{UO}_{2}$ should be released at the 
final time of the calculation, which is $16,800 \mathrm{~s}$. At these levels, plugging should not be a significant problem. Other recent work has estimated higher releases of uranium. The chief uncertainty in all of the uranium release estimates appears to be the choice of thermochemical data upon which vapor pressure curves are constructed. Finally, the timing estimates for uranium releases shown in Figure 16 should be useful for scheduling the opening and closing of the valves regulating flow through the filters during the test.

\subsection{Summary}

The recommendations in the recently completed independent peer review of the VICTORIA code are now being implemented. The plan is to address all of the highest priority recommendations before releasing the next code version, which will be named VICTORIA 2.0. The current schedule calls for this version to be released in the summer of 1998.

Recent work to support a regulatory initiative on the integrity of steam generator tubes has provided best estimates of releases to the environment. These predictions are for a temperature-induced steam generator tube rupture sequence using thermal-hydraulic data from SCDAP/RELAP5. The predictions are that about $30 \%$ of the iodine will be released to the environment if such an accident were to occur. About $12 \%$ of the cesium and tellurium would be released; releases of the other fission product elements would be less than $10 \%$.

Comparisons between VICTORIA predictions and preliminary release data from the Phebus FPT-1 test are remarkably good, with the single exception of molybdenum. Data for fission product deposition in the FPT-1 circuit, when they become available, should be useful for assessing the PRC recommendation to model three condensed phases rather than a single condensed phase, as in earlier versions of the VICTORIA code.

Pretest analyses of the Phebus FPT-4 test are being used to evaluate test protocol design and safety. VICTORIA predictions indicate that FPT-4 should be quite different than the other tests in the FP series because it uses a preformed rubble bed rather than fuel rods. Because of the direct contact between steam and fuel particles and because of the severe temperatures during this test, releases of the less volatile fission products, such as barium, strontium, and molybdenum, should be very high. Volatilization of uranium during this test is predicted to be low enough that filter plugging should not be a serious issue.

\section{References}

1. T. J. Heames, D. A. Williams, N. E. Bixler, A. J. Grimley, C. J. Wheatley, N. A. Johns, and M. D. Vine, P. Domagala, L. W. Dickson, C. A. Alexander, I. Osborn-Lee, S. Zawadzki, J. Rest, and H. S. Bond, "VICTORIA: A Mechanistic Model of Radionuclide Behavior in the Reactor Coolant System Under Severe Accident Conditions," Revision 1, SAND90-0756, NUREG/CR-5545, Sandia National Laboratories, Albuquerque, NM (1992).

2. V. Mubayi, J. A. Gieseke, D. R. Olander, and M. Schwarz, "VICTORIA Independent Peer Review," Technical Report W-6437 4-17-97, Brookhaven National Laboratory, Upton, NY (1997).

3. J. Rest and A. W. Cronenberg, "Modeling the Behavior of $\mathrm{Xe}, \mathrm{I}, \mathrm{Cs}, \mathrm{Te}, \mathrm{Ba}$, and $\mathrm{Sr}$ in Solid and Liquefied Fuel During Severe Accidents," J. of Nucl. Mat., 150, 203-225 (1987). 
4. N. E. Bixler and T. J. Heames, "VICTORIA-92-01 Validation Studies Against Data from the ORNL HI and VI, SNL ST, and CSNI ISP 34 (FALCON) Tests," SAND93-2301, Sandia National Laboratories, Albuquerque, NM, unpublished.

5. A. L. Wright, W. L. Pattison, and J. Y. King, "SERIES -2' Aerosol Resuspension Test Data Summary Report," Oak Ridge National Laboratory, Oak Ridge, TN, unpublished.

6. N. E. Bixler, "An Approach for Modeling Three Condensed Phases with VICTORIA," Letter Report to the USNRC, Sandia National Laboratories, Albuquerque, NM (1997).

7. P. E. Blackburn, "Oxygen Pressures Over Fast Breeder Reactor Fuel I: A Model for $\mathrm{UO}_{2 \pm \mathrm{x}}$," J. Nuc. Mat. 46, 244-252 (1973).

8. V. F. Urbanic and T. R. Heidrick, "High Temperature Oxidation of Zircaloy-2 and Zircaloy-4 in Steam," J. Nuc. Mat. 75, 251-261 (1978).

9. C. M. Allison, G. A. Berna, E. W. Coryell, K. L. Davis, D. T. Hagrman, J. K. Hohorst, R. R. Schultz, and L. J. Siefken, "SCDAP/RELAP5/MOD3.1 Code Manual Volume III: SCDAP/RELAP5 Users Guide and Input Manual," NUREG/CR-6150, EGG-2720, Idaho National Engineering Laboratory, Idaho Falls, ID (1993).

10. K. S. Quick and D. L. Knudson, "A SCDAP/RELAP5 Analysis of the Potential for Steam Generator Tube Rupture in Surry," Letter Report to the USNRC, Idaho National Engineering Laboratory, Idaho Falls, ID (1996).

11. N. E. Bixler, "VICTORIA Studies of Fission Product Release from an Induced Steam Generator Tube Rupture Sequence," Letter Report to the USNRC, Sandia National Laboratories, Albuquerque, NM (1997).

12. N. E. Bixler, "Analysis of Fission Product Behavior in the Phebus FPT-1 Test," Letter Report to the USNRC, Sandia National Laboratories, Albuquerque, NM (1997).

13. N. E. Bixler, "Pretest Analysis of Uranium Volatilization and Fission Product Release During the Phebus FPT-4 Rubble Bed Test," Letter Report to the USNRC, Sandia National Laboratories, Albuquerque, NM (1997).

14. B. Andre, G. Ducros, J. P. Leveque, M. F. Osborne, R. A. Lorenz, and D. Marco, "Fission Product Releases at Severe Light Water Reactor Accident Conditions: ORNL/CEA Measurements Versus Calculations," Nuc. Reactor Safety 114, 23-50 (1996).

15. C. M. Erickson and N. E. Bixler, "Boundary Coupling with VICTORIA," Letter Report to the USNRC, Sandia National Laboratories, Albuquerque, NM (1994). 